\title{
QUANTITATIVE ASSESSMENT OF INTERNAL COMPANY FACTORS OF COMPETITIVENESS
}

\author{
V. Milusheva* \\ Department of Industrial Business, UNWE - Sofia, Bulgaria
}

\begin{abstract}
PURPOSE: The purpose of this paper is to present a methodological workflow for assessing and analyzing the internal company factors to serve as a basis for developing a competitiveness improvement strategy.

METHODS: The methods envisaged in the proposed approach comprise a quantitative assessment and a benchmark analysis through which an assessment is made of the internal company factors at a given moment as well as a comparison with competitors. This can serve as a basis to highlight directions for developing a strategy.

RESULTS: The application of the approach allows to assess the actual status of the factors and their effect on the company's competitiveness.

CONCLUSIONS: Factors have various degrees of development for various periods of time. The higher the levels of these features for a given company, the higher its competitiveness and vice versa. High levels of all features from the proposed workflow are a sufficient condition to conclude that the company functions successfully. The progress in theory and methodology is indisputable, yet this is hardly true for the practical application of the approaches and methods suggested in the theory for assessing and analyzing the internal company factors facilitating the improvement of competitiveness.
\end{abstract}

Key words: competitiveness, industrial company, methods, assessment, analysis

\section{INTRODUCTION}

Business organizations represent complex systems within which take place many processes which have technical, economic and temporal parameters. Unlike external factors which comprise the environment in which companies develop, internal factors for enhancing their competitiveness are the result of conscious and deliberate actions of their managing bodies and their management. They, to a great extent, are defined by the action of external factors, yet they are dependent on the actions of the companies' leadership. They are the product of the efficacy of company's strategies and the effectiveness of their implementation.

The level of development of the internal factors defines the ability of a company to capitalize on favorable opportunities to enhance it's competitiveness provided by the external environment and to protect itself from threats originating from it. It is the internal

\footnotetext{
*Correspondence to: Vyara Milusheva, Department of Industrial Business, UNWE - Sofia, Bulgaria, 53 Radko Dimitriev St, Plovdiv, BULGARIA,vyara_milusheva@yahoo.com, 0899607093
}

factors which define the levels of the major indicators of company competitiveness and thus they define the type and scale of their competitive advantages.

The analysis of the internal company factors for enhancing competitiveness must commence by first assessing them.

\section{EXPOSITION}

Specialized literary sources $(1,2)$ offer a wide variety of classifications of factors for enhancing company competitiveness yet none of them has been uniformly accepted. This serves as a reason, for the purposes of this paper, to propose and use the classification of factors which represents an adaptation at a company level of competitiveness factors of countries developed by Fagerberg (3-4). This classifications includes a relatively small number of factors which facilitates studies. At the same time, it reflects features which are the cumulative result of a company's management efforts and sufficiently accurately represent its competitive capacities. It also takes account of the possibility for easy access to the information needed to make a quantitative assessment of the levels of the factors. 
The internal factors of competitiveness included in the analysis are as follows:

technology competitiveness - reflects the degree of innovativeness of a company and it refers to company's ability to compete successfully in markets for new goods and services;

- $\quad$ capacity competitiveness - reflects the ability of a company to rapidly and successfully develop, distribute and exploit its own and others' innovations;

cost (price) competitiveness refers to the level of the costs for creating and selling of unit of production, hence it also reflects the price level of production;

- product competitiveness is a precondition for good financial performance, however it is also a general criterion for the appropriateness and quality of all company efforts undertaken so far in a specific sector. High product competitiveness can be also achieved at the expense of the other business success indicators. For example, it may lead to worse financial performance of a company if it has been achieved at the expense of an unreasonably high costs (for product improvement, marketing promotion, etc.), or at the expense of a grossly reduced price. That is why it must be combined with the other indicators of enterprise competitiveness

- demand competitiveness - reflects the degree of correspondence between of a company's production structure and the composition of world demand.

These factors have priority when building the systems of indicators for assessing company competitiveness. The system of indicators however does not include the indicators for which information is difficult to obtain and some have been modified to be in line with the objectives of the analysis. An attempt is also made to define general factor ratings while taking account of the various relative weights of their composite indicators. In addition, the ratings of the indicators and factors are scores and have been scaled within the range from 1 to 7 . The lowest score of 1 represents very low level, and the highest score 7 - excellent condition. Assessment of internal factors of competitiveness is carried out in the following sequence:

Stage 1. Determination of the value of the indicators for evaluation of the level of each factor

1) Indicators for determining company's technology competitiveness

Indicators for determining technology competitiveness reflect (to the extent possible) company resources invested in research and development activity (Input) and the results achieved (Output). These are calculated as follows:

$$
I=\frac{R}{B}
$$

and

$O 1=\frac{P}{B}$,

$O 2=\frac{T}{B}$,

$O 3=\frac{O y}{B}$,

where:

$\mathrm{R}$ - company expenditure on $\mathrm{R} \& \mathrm{D}$ (thousand BGN);

B - number of employees in the company (number);.

$\mathrm{P}$ - number of product innovations implemented in the company throughout the year (number);

$\mathrm{T}$ - number of technological innovations implemented throughout the year (number);

$\mathrm{OY}$ - number of the organizational and management innovations;

I - R\&D costs per company employee (thousand BGN);

$\mathrm{O}_{1}, \mathrm{O}_{2}, \mathrm{O}_{3}$ - number of product, technology and organizational and management innovations implemented in the company per employee (number);

2) Indicators for determining company's capacity competitiveness

Indicators for determining capacity competitiveness reflect (to the extent possible) the quality and quantity of company's human capital, its ICT infrastructure and the diffusion of external innovation in the company. These are calculated as follows:

- $\quad$ quantity and quality of company's human capital:

$V=\frac{B v}{B}$

and

$C o=\frac{B c}{B}$

where:

$\mathrm{V}$ - relative share of company employees with higher education (number)

Co - relative share company employees with secondary vocational education (number)

$\mathrm{Bv}$ - number of company employees with higher education (number)

$\mathrm{Bc}$ - number of company employees with secondary vocational education (number)

- company's ICT infrastructure:

$I C T=\frac{\text { Aist }}{B}$

where: 
ICT - value of company's fixed ICT assets per employee (BGN thousand);

Aist - value of company's fixed ICT assets (computers, computer systems, software, etc.) (thousand BGN)

- diffusion of external innovations in the company:

$A=\frac{I d a}{B}$

and

$Z=\frac{Z a}{B}$

where:

A - investments made in company's fixed assets throughout the year per employee (thousand BGN);

$\mathrm{Z}$ - payments in the company throughout the year for using external fixed assets (for licensees, franchise fees, etc.) per company employee (thousand BGN):

Ida - investments made in company's fixed assets throughout the year (thousand BGN);

$\mathrm{Za}$ - payments in the company throughout the year for using external fixed assets (for licensees, franchise fees, etc.) (thousand BGN):

3) Indicator for determining company's cost (price) competitiveness

The indicator for determining cost (price) competitiveness of a company (Рк) takes account of unit labor costs. It is calculated as follows:

$R k=\frac{R t}{Q}$

where:

$\mathrm{Rt}$ - company's labor costs (thousand BGN);

$\mathrm{Q}$ - value of company production manufactured and sold (thousand BGN).

4) Indicators for determining product competitiveness comprise the relative perceived quality (RPQ) and product price.

In order to determine the relative perceived quality (RPQ), the following sequence of steps is used:

4.1.) Identification of the most important product features for the consumers (properties, parameters). Product features can be determined by experts.

4.2.) Determination of significance factor $\left(\mathrm{K}_{\mathrm{sig}}\right)$ for each of the identified parameters, i.e. the relative significance for each of them for the consumers. This is done through consumer surveys where consumers are asked to express their opinion on the significance of product characteristics. To that end, consumers are asked to evaluate each characteristic by assigning a weight ranging from 0 to 1 so that the total of the weights for all characteristics equals 1 , i.e. they must distribute the total rating of 1 among all parameters. Significance factors can also be determined by experts.

4.3.) Determination of the degrees (levels) to which each of the significant parameters, as defined by consumers, is developed (present) in the company's product and the competitors' products to which it is being compared. To that end, the group of consumers is given tables containing the indicators being assessed and a scale of the various degrees of their development from 1 to 7 (a score of 1 represents very low level, and the highest score 7 - excellent). Each user gives their assessment of the company's product and competitors' products for each of the indicators and results are then summarized. Although with a lower confidence level, ratings can be determined by experts.

4.4.) Determination of final ratings for each compared product for each characterizing indicator. This is done by multiplying the ratings for each indicator by their respective significance factors. The sum of ratings allows to determine a single overall consumer rating for the consumer value of the compared products, i.e. their relative perceived quality.

When determining the relative perceived quality, the following can be subjected to comparison: all products competing in that market and the product of the company, and the product of the major (the strongest) competitor in cases where the competitiveness of only two companies is being assessed.

5) Indicator for determining company's demand competitiveness. The indicator for determining demand competitiveness (Dk) is calculated as follows:

- Competitiveness in the domestic market

$$
\begin{aligned}
Д \kappa & =\sum_{i=1}^{n} M i j . G i=\sum_{i=1}^{n} \frac{X i j}{X t} \cdot G i, \\
G_{i} & =\frac{D y-D b y}{D b y},
\end{aligned}
$$

Demand competitiveness in the foreign market

$$
\begin{aligned}
& \not_{k}^{e}=\sum_{i=1}^{n} W i j \cdot G_{i}^{M}=\sum_{i=1}^{n} \frac{X_{i j}^{e}}{X_{t}^{e}} \cdot G_{i}^{M}, \\
& G_{i}^{M}=\frac{D_{y}^{M}-D_{b y}^{M}}{D_{b y}^{M}}
\end{aligned}
$$

where:

$\mathrm{i}$ - product groups sold by the $\mathrm{j}$ company $(\mathrm{i}=1 \div \mathrm{n})$;

$\mathrm{M}_{\mathrm{ij}}$ - relative share of sales of the i product group of the $\mathrm{j}$ company in the sectors for the baseline year; 
$\mathrm{W}_{\mathrm{ij}}$ - relative share of exports of the i product group of the $\mathrm{j}$ company in the sectoral exports for the baseline year (previous or other);

$G_{i}^{M}$ - increase in the sectoral demand for the i product group in the international market (EU market);

$\mathrm{G}_{\mathrm{i}}$ - increase in the sectoral demand for the $\mathrm{i}$ product group

$X_{i j}$ - value of the sales of the i product group of the $\mathrm{j}$ company in the sector for the baseline year;

$X_{t}$ - value of the sales of the sector for the baseline year;

$X_{i j}^{e}$ value of exports of the i product group of the $\mathrm{j}$ company for the baseline year;

$X_{t}^{e}$ - value of exports of the sector for the baseline year (EUR, \$);

$\mathrm{D}_{\mathrm{y}}$ and $D_{y}^{M}-$ demand for the i product group in the current year (EUR, \$), in the domestic and international market, respectively;

$\mathrm{D}_{\text {by }}$ and $D_{b y}^{M}$ - demand for the i product group for the baseline year (previous or other) (EUR, $\$$ ), in the domestic and international market, respectively;

The logic of the assessment is based on the understanding that a higher value of the indicator, and therefore higher value of the respective factors, is a sign of their more favorable impact on the company competitiveness, and their lower value - of a less favorable impact.

Stage 2. Determination of scores for the calculated indicators.

In case of assessing and comparing the competitiveness of a large number of companies, in order to determine their relative position (ranking):

$$
\mathrm{BO}_{\mathrm{ik}}=6 * \frac{(\text { CT ik }- \text { CT I min })}{(\text { CT imax }- \text { CT imin })}+1
$$

where:

$\mathrm{BO}_{\mathrm{ik}}-$ score for the $\mathrm{i}$ indicator for the $\mathrm{k}$ company;

$\mathrm{CT}_{\mathrm{ik}}$ - value of the $\mathrm{i}$ indicators for the $\mathrm{k}$ company;

$\mathrm{CT}_{\text {імах }}$ and $\mathrm{CT}_{\text {іміn }}$ - the respective maximum and minimum level (value) of the i indicator for the entire population of analyzed companies.

In case of assessing and comparing the competitiveness of only two companies (e.g. comparison with the main competitor), the company with the higher value of the indicator receives a score of 7 , and the rating of the other company is determined in accordance with the following formula:

$$
\mathrm{BO}_{\mathrm{ik}}=6 * \frac{C T i k}{C T i \max }+\mathbf{1}
$$

Stage 3. Determination of weighting factors At this stage, weighing factors for the individual indicators for assessing part of the factors are determined. Indicators' weighting factors show their various relative significance for the value of the respective factor.

Significance factors can be determined in three ways: by an expert assessment carried out by members of the research team; by studying the opinion of the managers surveyed, and by empirical studies.

Irrespective of the way employed to determine the weighting factors, when quantifying them it should be taken into account that the sum of the significance factors of all indicators for a specific factor must be one.

Stage 4. Assessment of the values of the indicators for internal factors of competitiveness

The assessment of company's technology competitiveness is carried out by using the scores for the indicators I, $\mathrm{O}_{1}, \mathrm{O}_{2}$ and $\mathrm{O}_{3}$ :

$T_{k}=w_{1} I+w_{2} O_{1}+w_{3} O_{2}+w_{4} O_{3}$

where:

$\mathrm{w}_{1}, \mathrm{w}_{2}, \mathrm{~W}_{3}$ and $\mathrm{w}_{4}$ - significance factors.

The assessment of company's capacity competitiveness is carried out as follows:

$K_{K}=w_{1} V+w_{2} C o+w_{3} I C T+w_{4} A+$

$w_{5} Z$

where:

$\mathrm{W}_{1}, \mathrm{~W}_{2}, \mathrm{~W}_{3}, \mathrm{~W}_{4} \mathrm{U}$ w5 - significance factors.

The assessment of individual product's competitiveness is carried out in accordance

with the formula: $\mathrm{CP}=\mathrm{RPQ} / \mathrm{P}$

where:

$\mathrm{CP}$ - competitiveness of an individual product; RPQ - relative perceived quality of the product (score);

$\mathrm{P}$ - product price (score).

The assessment of demand competitiveness is carried out as per the formula:

Кт $=\mathrm{w} 1$ Дк $+\mathrm{w} 2 Д \kappa е$

$\mathrm{W}_{1}$ and $\mathrm{W}_{2}-$ significance factors.

The assessment of the levels of the internal factors for enhancing company competitiveness allows to reveal company's strengths and weaknesses and, based on that, to take reasoned managerial decisions. Also, comparisons can be made with other companies from the sector, with similar companies from other countries, with the 
condition of the respective field across Europe and around the world.

\section{CONCLUSION}

The values achieved for each of the indicators identified shows the extent to which companies are able to use internal factors and also serve as a ground to define strengths and weaknesses the influence on which will result in the enhancement of their competitive positions. All this is of crucial importance for developing companies and achieving long-term success.

\section{REFERENCES}

1. Mladen, V., Otsenka I analiz na firmenata konkurentosposobnost, Sofia., pp. 53,56,58, 61, 103, 2004

2. SHAFAEI R., An analytical approach to assessing the competitiveness in the textile industry, Journal of Fashion Marketing and Management, Vol13 No1, p.20-36, 2009

3. Fagerberg, J., Technology, Growth and Competitiveness; Jan Fagerberg, Technology and Competitiveness, Oxford Review of Economic Policy 12: 39-51, 2002

4. Fagerberg, J., Knell, M. and Srholec, M., The Competitiveness of Nations: Economic Growth in the ECE Region, 2004 